\title{
Identifikasi rantai distribusi dan kajian rantai nilai produk bawang merah (Allium cepa l.) Kabupaten Rote Ndao
}

\section{Distribution chain identification and value chain study of shallots (Allium cepa l.) Rote Ndao Regency}

\author{
Gregorius Gehi Batafor ${ }^{\mathrm{a}}$ \\ aPoliteknik Pertanian Negeri Kupang \\ E-mail: gregorius.batafor@gmail.com \\ Naskah Diterima : 18 Agustus 2019; Di-review : 19 Agustus 2019; Dimuat: 30 Agustus 2019
}

Copyright OFLOBAMORA 2019

\begin{abstract}
This study aims to identify the distribution chain and study the value chain of shallot products originating from Rote Ndao Regency so that it can map which actors get the most economic benefits in the product distribution chain. The research methodology was conducted using descriptive questionnaires; value added analysis using the Hayami method and principal cost analysis. The respondents are onion stakeholders consisting of farmers, collectors to retailers in Naikoten Inpres Market. Value chain analysis is performed on the type of removable onion and askip. The identification results of the shallot distribution chain involve stakeholders, farmers, intermediary / intermediary traders who deliver inter-island shipping, and retailers in the Naikoten Inpres Market. While value chain studies show that farmers get lower economic benefits than collectors and retailers, both red onion and askip. The $R C$ ratio is also lower, namely 1.0196 for removable shallots, $R C$ ratio of 0.9994 for curing without askip, and RC ratio of 1.0072 for shallots with askip. For collectors, the RC Ratio value of 1.0093 for the type of removable shallot. Whereas for retailers, the RC Ratio value is 1.2163 for the type of removable shallot, and the RC Ratio value is 1.0701 for shallots with the process of askip.
\end{abstract}

Keywords : Distribution Chain; Value Chain; Shallot; Rote Ndao Regency; Value Added Analysis.

\section{Abstrak}

Penelitian ini bertujuan untuk mengidentifikasi rantai distribusi dan mengkaji rantai nilai pada produk bawang merah yang berasal dari Kabupaten Rote Ndao sehingga dapat memetakan pelaku mana yang paling banyak mendapatkan manfaat ekonomis dalam rantai distribusi produk tersebut. Metodologi penelitian dilakukan dengan menggunakan kuesioner deskriptif, analisis nilai tambah menggunakan metode hayami dan analisis biaya pokok. Respondennya merupakan stakeholders bawang merah terdiri dari para petani, pedagang pengumpul hingga pedagang pengecer di Pasar Inpres Naikoten. Analisis rantai nilai dilakukan pada jenis bawang merah lepasan dan askip. Hasil identifikasi rantai distribusi bawang merah melibatkan stakeholders para petani, pedagang pengumpul/perantara yang melakukan pengiriman antar-pulau, dan pedagang pengecer di Pasar Inpres Naikoten. Sedangkan kajian rantai nilai menunjukkan bahwa para petani mendapatkan manfaat ekonomis lebih rendah daripada pedagang pengumpul dan pedagang pengecer, baik bawang merah lepasan maupun askip. Nilai RC rasionya pun lebih rendah yaitu 1,0196 untuk bawang merah lepasan, RC rasio 0,9994 untuk proses curing tanpa askip, dan RC rasio 1,0072 untuk bawang merah dengan proses askip. Pada pedagang pengumpul, nilai RC Ratio 1,0093 untuk jenis bawang merah lepasan. Sedangkan untuk pedagang pengecer memiliki nilai RC Ratio 1,2163 untuk jenis bawang merah lepasan, dan nilai RC Ratio 1,0701 untuk bawang merah dengan proses askip. 


\section{Pendahuluan (Time New Roman, 10 Bold)}

Bawang merah merupakan komoditi yang dibutuhkan oleh masyarakat Indonesia sehari-hari sehingga bila terjadi fluktuasi pasokan akan menyebabkan fluktuasi harga. Bawang merah dapat diproduksi sepanjang tahun namun sebaran per bulan tidak merata, sedangkan bagi konsumen individu, bawang merah dibutuhkan dalam jumlah sedikit, kontinu dan tidak tergantikan oleh komoditi lain. Seringkali petani di sentra produksi pada saat panen raya berada dalam posisi yang lemah. Hal ini karena harga yang rendah bila ingin dijual atau mengalami susut yang tinggi bila disimpan dan akan dijual pada saat harga stabil. Menurut Dirjen P2HP Kementerian Pertanian (2016) susut pada komoditas bawang mencapai $30-40 \%$. Walaupun tidak saat panen raya pun, tingginya harga bawang di tingkat pengecer dan pasar modern tidak terdistribusi dengan baik ke tingkat petani sehingga petani memperoleh porsi pendapatan terkecil dan fluktuatif (Nurasa dan Darwis, 2007).

Analisis rantai nilai diperlukan untuk mengetahui pelaku mana yang perlu perbaikan input untuk meningkatkan nilai tambah (Stephen, 2008). Pendekatan rantai nilai membantu memahami bagaimana kondisi membentuk rantai nilai, melakukan identifikasi siapa yang menanganinya, menjawab pertanyaan yang luas dan spesifik, serta melakukan pendekatan membangun hubungan kemitraan (Bahtiar dan Kindangen, 2011).

Tabel 1. Jumlah Produksi, Luas Panen dan Tingkat Produktivitas Bawang Merah Menurut Kabupaten/Kota di Provinsi Nusa Tenggara Timur Tahun 2017

\begin{tabular}{|c|c|c|c|}
\hline $\begin{array}{c}\text { Mama } \\
\text { Kalhupaten }\end{array}$ & $\begin{array}{l}\text { Wontah Prodhtsi } \\
\text { Bawrang Merah } \\
\text { [Ton] }\end{array}$ & $\begin{array}{l}\text { Luas Panen } \\
\text { Bawwang Merah } \\
\text { [(Ha)] }\end{array}$ & $\begin{array}{l}\text { Tinglatt } \\
\text { Prochltimitas } \\
\text { [Ton/fla] }\end{array}$ \\
\hline Sumba Barat & 22,70 & 2 & 11,35 \\
\hline Sumba Timur & $40^{\circ}$ & 5 & $\mathbf{s}$ \\
\hline Kupane & 2651,80 & 19 & 139,57 \\
\hline$\pi \mathrm{s}$ & 1032 & 28 & 36,86 \\
\hline Tru & 80,40 & 9 & 8,93 \\
\hline Behu & 216,90 & 11 & 19,72 \\
\hline Alor & 71 & o & 0 \\
\hline Lembata & $\mathbf{7 6 , 4 0}$ & o & o \\
\hline Fkores Trimur & 9 & o & o \\
\hline stata & 67,20 & $\mathbf{1}$ & 67,20 \\
\hline Ende & 50,50 & $\mathbf{1}$ & 50,50 \\
\hline Mgach & 0 & 6 & o \\
\hline Manezarai & 76,20 & o & o \\
\hline Roche Wdao & 2435,60 & $\mathbf{s}$ & 304,45 \\
\hline Manezarai Barat & 373 & o & 0 \\
\hline Sumba Tengah & 1,60 & o & o \\
\hline Sunba Barat Daya & 6,40 & o & o \\
\hline Magekeo & 105 & o & o \\
\hline Manezarai Trmur & 411,90 & 9 & 45,77 \\
\hline 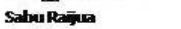 & 27 & o & 0 \\
\hline Malata & o & o & o \\
\hline Kota Kupang & 17,50 & o & o \\
\hline mos Tenezara Tumur & $7.772,10$ & 99 & 78,51 \\
\hline
\end{tabular}

Sumber: Data Diolah

Kabupaten Rote Ndao berada di Nusa Tenggara Timur merupakan kabupaten dengan jumlah produksi bawang merah terbesar kedua, yaitu mencapai 2.435,60 ton di tahun 2017, setelah Kabupaten
Kupang yang menghasilkan 2.651,80 ton. Namun apabila diukur dari tingkat produktivitas yaitu jumlah produksi dibandingkan dengan luas panen, maka Kabupaten Rote Ndao merupakan kabupaten yang memiliki tingkat produktivitas tertinggi dibandingkan dengan kabupaten lainnya, yaitu mampu menghasilkan 304,45 ton/hektar (BPS Provinsi NTT, 2018). Berikut disajikan tabel jumlah produksi dan luas panen bawang merah menurut kabupaten/kota di Provinsi Nusa Tenggara Timur pada tahun 2017.

Dari tabel 1, dapat dijelaskan bahwa pada tahun 2017 Kabupaten Rote Ndao mampu menghasilkan 2.435,60 ton bawang merah hanya dengan luas panen $8 \mathrm{Ha}$. Hal ini menunjukkan bahwa para petani bawang merah di kabupaten ini memiliki tingkat produktivitas yang tinggi, apabila dibandingkan dengan petani-petani bawang merah pada kabupaten lainnya di wilayah Nusa Tenggara Timur.

Meskipun demikian, kondisi ini tidak langsung menjelaskan tentang tingkat kesejahteraan para petani bawang merah, hal ini dikarenakan beberapa hasil penelitian yang salah satunya dilakukan oleh Nurasa dan Darwis (2007), menyatakan bahwa walaupun tidak saat panen raya pun, tingginya harga bawang di tingkat pengecer dan pasar modern tidak terdistribusi dengan baik ke tingkat petani sehingga petani memperoleh porsi pendapatan terkecil dan fluktuatif.

Penelitian ini bertujuan untuk: (i) mengidentifikasi rantai distribusi dan mengkaji rantai nilai yang terjadi pada produk bawang merah yang dihasilkan oleh para petani di Kabupaten Rote Ndao (ii) memetakan manfaat ekonomis berdasarkan rantai nilai yang terjadi dalam rantai distribusi produk bawang merah tersebut.

\section{Kerangka Teori}

\subsection{Rantai Nilai}

Posisi gambar dan tabel berada pada awal atau akhir kolom. Hindari penempatan pada tengah kolom. Gambar besar dan tabel dapat diperlebar memenuhi kedua kolom.

Analisis rantai nilai menurut Kaplinsky (1999) harus mengacu pada serangkaian kegiatan yang diperlukan untuk mengadakan suatu komoditas produk yang dimulai dari tahap konseptual, dilanjutkan dengan beberapa tahap produksi, hingga pengiriman ke konsumen akhir. Rantai nilai terbentuk ketika semua pelaku dalam rantai tersebut beraktifitas sedemikian rupa sehingga memaksimalkan terbentuknya nilai sepanjang rantai tersebut. Definisi ini dapat diartikan secara sempit maupun luas. Pada definisi dalam arti sempit, suatu rantai nilai mencakup serangkaian kegiatan yang dilakukan di dalam suatu perusahaan untuk menghasilkan keluaran tertentu. Sedangkan 
definisi rantai nilai berdasarkan pendekatan yang luas melihat berbagai kegiatan kompleks yang dilakukan oleh berbagai pelaku (produsen utama, pengolah, pedagang, penyedia jasa) untuk membawa bahan baku melalui suatu rantai hingga menjadi produk akhir yang dijual. Rantai nilai ini dimulai dari sistem produksi bahan baku yang akan terus terkait dengan kegiatan usaha lainnya dalam perdagangan, perakitan, pengolahan, dan lain-lain. Rantai nilai merupakan alat yang dapat digunakan stakeholders untuk menentukan sumber keunggulan kompetitif. Porter (1985), menyatakan bahwa perlunya meningkatkan keunggulan kompetitif perusahaan dengan membandingkan dua strategi utama yaitu strategi pengurangan harga dan strategi diferensiasi. Pada strategi pengurangan harga yaitu bagaimana menentukan suatu kegiatan dapat memberi konsumen nilai yang setara dari produk pesaing namun diperoleh dengan biaya yang lebih murah sedangkan strategi diferensiasi yang menentukan kegiatan menghasilkan produk lebih mahal tapi konsumen mau membayar lebih. Analisis rantai nilai membantu kegiatan atau strategi yang dipilih oleh pelaku usaha agar memperoleh keunggulan kompetitif.

\subsection{Kajian Rantai Nilai Pada Sektor Pertanian}

Menurut ACIAR (2012) dalam mengkaji rantai nilai pada sektor pertanian terdapat empat aspek yang dianggap penting untuk dapat dianalisis. Pertama, suatu analisis rantai nilai melakukan pemetaan secara sistematis para pelaku yang berpartisipasi dalam produksi, distribusi, pemasaran, dan penjualan suatu produk atau komoditas pertanian. Pemetaan ini mengkaji ciri-ciri berbagai pelaku, struktur laba-rugi, aliran barang di sepanjang rantai, ciri ketenagakerjaan, serta tujuan dan volume penjualan lokal dan nonlokal (Kaplinsky dan Morris 2001). Data dan informasi tersebut dapat dikumpulkan dari kegiatan atau gabungan kegiatan berupa kegiatan survei langsung, diskusi kelompok terfokus, pengkajian pedesaan secara partisipatif (PRA), wawancara informal, dan data sekunder.

Kedua, analisis rantai nilai dapat memainkan peran utama dalam mengidentifikasi distribusi manfaat bagi para pelaku dalam rantai nilai. Melalui analisis margin dan laba ataupun dengan Rasio Revenue per Cost di dalam rantai nilai, dapat dilihat siapa saja yang memperoleh manfaat dari partisipasi dalam rantai nilai dan pelaku mana yang dapat memperoleh manfaat dari dukungan teknologi atau pengorganisasian yang lebih baik.

Ketiga, analisis rantai nilai dapat digunakan untuk mengkaji peran peningkatan dalam rantai nilai. Peningkatan dapat mencakup peningkatan dalam hal kualitas, umur simpan dan desain produk, atau diversifikasi dalam lini produk yang dilayani, yang memungkinkan produsen mendapatkan nilai yang lebih tinggi. Beberapa kasus peran peningkatan rantai nilai komoditas pertanian dilakukan dengan mengurangi losses pada saat pascapanen dengan menggunakan teknologi yang memadai. Suatu analisis terhadap proses peningkatan mencakup adanya kajian atas seberapa besar laba yang dapat diperoleh para pelaku di dalam rantai nilai, serta informasi tentang keterbatasan yang ada.

Keempat, analisis rantai nilai mengkaji peran tata kelola dalam rantai nilai, yang dapat bersifat internal maupun eksternal. Tata kelola dalam suatu rantai nilai mengacu pada struktur hubungan dan mekanisme koordinasi yang terjadi antara para pelaku dalam rantai nilai. Tata kelola merupakan konsep yang luas yang pada dasarnya memastikan bahwa interaksi antara para peserta di dalam rantai nilai telah terorganisir, dan bukan hanya sekedar terjadi secara acak. Umumnya, tata kelola dalam rantai nilai terjadi ketika beberapa pelaku bekerja dengan memenuhi kriteria yang ditetapkan oleh pelaku lainnya dalam rantai nilai tersebut. pada kasus cabe dalam FAO (2012), terdapat standar mutu atau waktu pengiriman, insentif dan volume yang ditetapkan oleh industri pengolahan cabe pada koperasi petani serta hubungan tata kelolanya terhadap para petani cabe.

ACIAR (2012) menyatakan bahwa alat analisis rantai nilai terbagi menjadi tiga jenis yaitu alat umum, alat kualitatif dan alat kuantitatif. Setiap jenis alat memiliki beberapa aktivitas. Alat umum aktivitasnya meliputi penentuan prioritas rantai nilai yang akan dianalisis dan setelah itu melakukan pemetaan rantai nilai. Alat kualitatif terdiri dari analisis tata kelola (koordinasi, regulasi dan kendali), analisis keterkaitan dan kepercayaan, serta analisis pilihan untuk peningkatan berdasarkan permintaan baik pengetahuan, ketrampilan, teknologi maupun layanan pendukung. Alat kuantitatif aktivitasnya meliputi analisis biaya dan marjin, analisis distribusi pendapatan dan analisis distribusi lapangan pekerjaan. Setiap aktivitas pada setiap jenis alat memilki langkah-langkah yang harus dilakukan dalam menganalisis rantai nilai. Pada aktivitas penentuan prioritas langkahnya yaitu penentuan kriteria, penentuan bobot kriteria, identifikasi daftar produk/kegiatan dan penetapan produk/kegiatan. Sedangkan untuk aktvitas pemetaan rantai nilai aktivitasnya terdiri dari pemetaan proses inti, identifikasi dan pemetaan pelaku utama yang terlibat, pemetaan aliran produk,pemetaan pengetahuan dan alur informasi, pemetaan volume dan jumlah pelaku, pemetaan alur geografis produk, pemetaan nilai pada berbagai tingkatan dalam rantai nilai, pemetaan hubungan keterkaitan antara pelaku rantai nilai, pemetaan layanan dan pemetaan hambatan serta solusinya.

Pada jenis alat kuantitatif terdapat aktivitas analisis biaya dan marjin yang memiliki langkahlangkah penghitungan biaya peluang dan biaya keuangan, penghitungan biaya investasi yang diperlukan, penghitungan penerimaan per pelaku, 
penghitungan rasio keuangan, perubahan keuangan yang terjadi dalam kurun waktu tertentu, posisi keuangan relatif para pelaku dan penetapan benchmarking. Setelah aktivitas analisis biaya dan marjin, lalu melakukan analisis distribusi pendapatan yang meliputi penetapan kategori, penghitungan pendapatan per unit keluaran, penghitungan pendapatan bersih di tiap tingkatan rantai nilai serta penghitungan distribusi pendapatan upah dan distribusi nilai tambah.

\subsection{Penelitian-Penelitian Mengenai Rantai Nilai}

Menurut Kumar et al (2004) terdapat keunggulan ekonomis yang jelas dalam produksi sayuran, bila dibandingkan dengan produk lain namun kekurangan fasilitas marketing telah menjadi hambatan utama. Biaya transportasi dan marjin pemasaran baik retailer maupun pasar induk diidentifikasi sebagai penyebab utama tingginya biaya pemasaran sayuran yang berdampak pada keuntungan produk. Navadkar et al (2005) telah mengangkat isu tingginya biaya pengemasan, tingginya komisi, tingginya biaya transportasi dan penundaan pembayaran ke petani serta adanya malpraktek dalam pemasaran sayuran seperti tindakan spekulatif penimbunan. Khunt et al (2006) menyatakan bahwa terdapat hubungan negatif yang signifikan antara kedatangan pasar dengan harga sayuran. terdapat variasi dalam sharing petani berdasarkan perbedaan saluran pemasarannya.

Sidhu et al (2010) telah melakukan penelitian rantai pasok bawang merah di Punjab, India dengan melakukan analisis biaya dan pendapatan ditingkat petani. Dari hasil penelitiannya menunjukkan bahwa umumnya petani memasok bawang ke agen/pengumpul (lebih dari 90\%, diikuti ke pengecer dan ke konsumen langsung. Menurutnya efisiensi pemasaran dapat ditingkatkan melalui kompetisi antar rantai pengecer dan perubahan harga disuatu tempat mempengaruhi perubahan harga ditempat lain. Terdapat tiga saluran pemasaran bawang merah, Sidhu et al (2010) menggunakan analisis RC rasio dan marjin dalam penelitiannya dengan hasil 2,5 untuk RC rasionya dan 74.547 rupee untuk marjin petaninya.

Prihatiningsih (2007) telah melakukan penelitian mengenai efisiensi saluran pemasaran bawang merah dikota Bogor, menurutnya terdapat 16 saluran pemasaran bawang merah di Kota Bogor. Dari hasil penelitiannya terdapat saluran pemasaran yang paling efisien karena selisih harga petani dengan harga konsumen hanya sebesar 1800 rupiah. Saluran pemasaran ini terdiri dari pengirim, pedagang besar di Pasar Induk Kemang dan pedagang pengecer di Pasar Baru Bogor. Model transshipment menghasilkan alokasi bawang merah yang meminimalkan biaya pasokan bawang merah ke pasar-pasar di Kota Bogor.

Endrasri dan Prayudi (2011) telah menginventarisi teknologi penanganan bawang merah beserta pengolahannya untuk meningkatkan nilai tambah. Salah satunya adalah pengeringan di atas para-para dan dibalik setiap dua hari. Menurutnya pengeringan ini dilakukan setelah pemanenan hingga bawang merah mencapai kondisi askip sehingga kondisi kering mempunyai daya tahan simpan 2-3 bulan. Hal ini dapat mengurangi susut sehingga mampu meningkatkan nilai tambah

\subsection{Nilai Tambah Produk Pertanian}

Penomoran persamaan dilakukan secara berurutan, dengan nomor persamaan ditulis di dalam tanda kurung dan rata kanan, contohnya (1). Untuk penulisan kuantitas

Menurut Hayami et al. (1987) ada dua cara untuk menghitung nilai tambah yaitu nilai tambah untuk pengolahan dan nilai tambah untuk pemasaran. Faktor-faktor yang mempengaruhi nilai tambah pengolahan dapat dikaterogikan menjadi dua yaitu faktor teknis dan faktor pasar. Faktor teknis yang berpengaruh adalah kapasitas produksi, jumlah bahan baku yang digunakan dan tenaga kerja. Faktor pasar yang berpengaruh adalah harga output, upah tenaga kerja, harga bahan baku dan nilai input lain selain bahan baku dan tenaga kerja. Besarnya nilai tambah karena proses pengolahan didapat dari pengurangan biaya bahan baku dan input lain terhadap nilai produk yang dihasilkan, tidak termasuk tenaga kerja.

Nilai tambah berhubungan dengan teknologi yang diterapkan dalam proses pengolahan, kualitas tenaga kerja berupa keahlian dan ketrampilan serta kualitas bahan baku. Penerapan teknologi yang cenderung padat karya akan memberikan proporsi terhadap tenaga kerja dalam jumlah lebih besar dari pada melihat langsung keuntungan bagi perusahaan, sedangkan apabila yang diterapkan padat teknologi yang berpengaruh terhadap modal maka besarnya proporsi bagian pengusaha lebih besar dari pada proporsi bagian tenaga kerja. Besar kecilnya proporsi tersebut tidak berkaitan dengan imbalan yang diterima tenaga kerja (dalam rupiah). Besar kecilnya imbalan tenaga kerja tergantung pada kualitas tenaga kerja itu sendiri seperti keahlian dan ketrampilan. Kualitas bahan baku juga berpengaruh terhadap pemasaran nilai tambah apabila dilihat dari produk akhir. Jika faktor konversi bahan baku terhadap produk akhir semakin lama semakin kecil, artinya pengaruh kualitas bahan baku semakin lama semakin besar.

Salah satu metode analisis nilai tambah pengolahan yang sering digunakan adalah yang dikemukakan oleh Hayami et al. (1987). Kelebihan dari model analisis yang digunakan oleh Hayami et al. (1987) adalah: (1) lebih cepat digunakan untuk proses pengolahan produk-produk pertanian, (2) dapat diketahui produktivitas produknya, (3) dapat diketahui balas jasa bagi pemilik-pemilik faktor produksi dan (4) dapat dimodifikasi untuk analisis nilai tambah selain sub sistem pengolahan. 
Menurut Balk (2002), nilai tambah diperoleh dari perbedaan antara penerimaan dan biaya-biaya yang dikeluarkan, yaitu biaya service, biaya energi dan biaya material. Menurut Coltrain et al. (2000) nilai tambah adalah menambah nilai produk dengan mengubah tempat, waktu dan bentuk menjadi lebih disukai oleh konsumen dalam pasar. Terdapat dua jenis nilai tambah, yaitu inovasi dan koordinasi.

Kegiatan inovasi merupakan aktivitas yang memperbaiki proses yang ada, prosedur, produk dan pelayanan atau menciptakan sesuatu yang baru dengan menggunakan atau memodifikasikan konfigurasi organisasi yang telah ada, sedangkan pengertian dari koordinasi merupakan harmonisasi fungsi dalam keseluruhan bagian sistem. Hal tersebut merupakan peluang dalam meningkatkan koordinasi produk, pelayanan informasi dalam proses produksi pertanian untuk menciptakan imbalan yang nyata dan meningkatkan nilai produk dalam setiap tahap proses produksi pertanian. Konsep nilai tambah bukan hanya terbatas pada fisik produk, tetapi juga pelayanan (service) yang diciptakan (Boade, 2003).

\section{Metode}

\subsection{Lokasi dan Waktu Penelitian}

Penelitian dilakukan di Kabupaten Rote Ndao Provinsi Nusa Tenggara Timur. Pemilihan lokasi dilakukan secara sengaja (purposive), dengan pertimbangan bahwa kabupaten ini merupakan sentra produksi bawang merah yang memiliki tingkat produktivitas tertinggi di Nusa Tenggara Timur. Pada tingkat rantai distribusi, dilakukan penelitian pada tingkat petani di wilayah Rote Ndao, beberapa pedagang pengumpul baik di Rote Ndao maupun di Kota Kupang, dan para pedagang pengecer pada pasar rakyat yang ada di Kota Kupang, dimana pasar tersebut merupakan tujuan utama pengiriman bawang merah. Pelaksanaan kegiatan penelitian dilakukan pada bulan Juni-November 2018.

\subsection{Jenis dan Sumber Data}

Data yang digunakan dalam penelitian ini meliputi data primer dan data sekunder. Data primer diperoleh melalui pengamatan langsung (observasi), pengisian kuisioner di tingkat petani, pedagang pengumpul dan pedagang pengecer.

Data primer yang bersumber dari petani bawang merah mengenai luas tanam, produktivitas, biaya produksi, jumlah bawang merah yang diproduksi, jumlah yang dihasilkan dari curing, jumlah yang sudah melalui pengeringan askip, susut disetiap tindakan pascapanen, harga jual, biaya tenaga kerja untuk pengeringan askip. Data primer yang diperoleh dari pengirim dan pedagang berupa biaya transportasi, susut transportasi, susut renstan, biaya tenaga kerja dan biaya sewa lapak. Sedangkan data sekunder diperoleh dari berbagai sumber literatur meliputi buku pustaka, jurnal dan berbagai literatur pendukung lainnya.

Penelitian dibagi menjadi tiga aktivitas yaitu identifikasi rantai distribusi, mengkaji rantai nilai dan pemetaan manfaat ekonomis. Pengkajian rantai nilai pada tingkat petani dilakukan dengan menghitung biaya produksi, jumlah produksi, jumlah yang dihasilkan dari curing, jumlah produk yang sudah melalui pengeringan askip, susut di setiap tindakan pascapanen, harga jual, biaya tenaga kerja untuk pengeringan askip. Pada tingkat pedagang pengumpul dan pedagang pengecer, kajian rantai nilai dilakukan dengan menghitung biaya transportasi, susut transportasi, susut renstan, biaya tenaga kerja dan biaya sewa lapak. Responden terdiri dari 30 orang petani di wilayah Rote Ndao, 5 orang pedagang pengumpul dan 5 orang pedagang pengecer pasar rakyat yaitu di Pasar Inpres Naikoten.

\subsection{Teknik Analisis Data}

Analisis nilai tambah menggunakan metode Hayami. Data-data yang diperlukan pada metode Hayami untuk menghitung nilai tambah berupa jumlah output, bahan baku dan tenaga kerja per periode. Selain itu data harga output, upah rata-rata, harga bahan baku dan biaya sumbangan input lain juga diperlukan. Adapun istilah yang digunakan dalam metode Hayami tersebut disesuaikan dengan istilah yang ada dalam proses penyimpanan dan perdagangan bawang merah. Sebagai contoh yaitu istilah faktor konversi dalam Hayami disesuaikan menjadi persentasi hasil setelah dikurangi susut penyimpanan.

Langkah-langkah yang dilakukan dalam menganalisis nilai tambah menurut metode Hayami et al. (1987) adalah:

1. Membuat arus komoditas yang menunjukkan bentuk-bentuk komoditas, lokasi, lama penyimpanan dan perlakuan yang pernah diberikan kepada komoditas bersangkutan;

2. Mengidentifikasikan setiap transaksi yang terjadi menurut perhitungan finansial;

3. Memilih dasar perhitungan.

Beberapa variabel yang terkait dalam analisis nilai tambah, yaitu:

1. Faktor konversi, menunjukkan ouput yang dihasilkan satu satuan input;

2. Koefisien tenaga kerja langsung, menunjukkan tenaga kerja langsung yang diperlukan untuk mengolah satu satuan input;

3. Nilai output, menunjukkan nilai ouput yang dihasilkan dari satu satuan input.

Analisis biaya meliputi biaya tetap, biaya tidak tetap, total biaya, kapasitas dan biaya pokok. Biaya tetap adalah jenis-jenis biaya yang selama satu periode kerja tetap jumlahnya. Total biaya dihitung menggunakan persamaan [1], yang merupakan biaya keseluruhan yang diperlukan untuk operasional yang merupakan penjumlahan dari biaya tetap dan biaya 
tidak tetap. Biaya pokok dihitung menggunakan persamaan [2], yaitu biaya yang diperlukan pada saat penanganan pasca panen untuk setiap $\mathrm{kg}$ bawang merah.

Tabel 2. Analisis Nilai Tambah

Metode Hayami (1987)

\begin{tabular}{|c|c|c|}
\hline \multicolumn{3}{|c|}{ O-1et, Inpt dan Harga } \\
\hline 1 & Ontput (kgperionde) & $\mathbf{A}$ \\
\hline 2 & Bahan Baku(kgtperiode) & B \\
\hline 3 & Tenaga Keja (HOW/periode) & $\mathbf{c}$ \\
\hline 4 & Faktor Konvexi (Kg oudput/Kgbahanbakn) & $\mathbf{D}=\mathbf{A} / \mathbf{B}$ \\
\hline 5 & Kneefision temag keja (HOK/Kg Bahan Baka) & $\mathbf{E}=\mathbf{C} / \mathbf{B}$ \\
\hline 6 & Hang Oupat ( $\left(\mathbf{R}_{\mathrm{P}} / \mathrm{K}_{\mathrm{g}}\right)$ & $\mathbf{F}$ \\
\hline 7 & Upahnta-sita temaq keja ( $\left.\mathrm{R}_{\mathrm{P}} / \mathrm{HOK}\right)$ & $\mathbf{G}$ \\
\hline \multicolumn{3}{|c|}{ 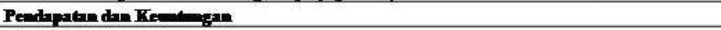 } \\
\hline 8 & Hang bahanbaka(Rp/Kg) & H \\
\hline 9 & Sumbangminpot lin $\left(R_{\mathbf{P}} / \mathbf{K}_{\mathbf{g}}\right)$ & I \\
\hline 10 & Nhai outpat (Rp/Ke) & SODxF \\
\hline 112 & Nai tambah ( $\left(\mathbf{R}_{\mathbf{p}} / \mathrm{K}_{\mathrm{g}}\right)$ & $\mathbf{K}=\mathbf{H} \mathbf{H}$ \\
\hline b. & Rasionthi tambah( (x) & $L X=(K / J)=100 \%$ \\
\hline 122 & Imbalmintenagp keja $\left(R_{p} / K_{p g}\right)$ & $\mathbf{M}=\mathbf{E x G}$ \\
\hline b. & Bagiantenagikeja (\%) & $N \times=(M / K)=100 \%$ \\
\hline 132 & Kentungm $\left(\mathbf{R p}_{\mathrm{p}} / \mathrm{K}_{\mathrm{q}}\right)$ & O=KM \\
\hline b. & Fingatkentumgen( $(8)$ & $F X=(\alpha /)=100 \%$ \\
\hline \multicolumn{3}{|c|}{ 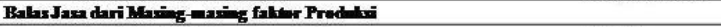 } \\
\hline 14 & Mä̈n $\left(R_{p} / K_{q}\right)$ & $\mathrm{O}-(\mathbf{H H})$ \\
\hline & Imbalmintengapejaja (x) & R* $=(M / O) \times 100 \%$ \\
\hline & Sambangen inpthin ( ()$_{)}$ & $S x=(U(1))=100 \%$ \\
\hline$=$ & Kountungm ( $(\%)$ & $T W=(O Y O) \times 100 \%$ \\
\hline 15 & RCnsis & $\mathbf{U}=\mathbf{V}(\mathbf{H}+\mathbf{H} \mathbf{M})$ \\
\hline
\end{tabular}

Sumber: Hayami (1987)

Berikut rumus perhitungannya (Gittinger JP, 1972):

$$
B=\frac{B T}{x}+B T T
$$

$B p=\frac{B}{k}$

$B=$ Biaya Total (Rp/Bulan); BT = Biaya Tetap (Rp/Tahun); BTT = Biaya Tidak Tetap (Rp/Bulan); $x$ $=$ Perkiraan bulan kerja per tahun; $k=$ Kapasitas alat (kg/bulan); Bp = Biaya pokok ( $\mathrm{Rp} / \mathrm{kg})$.

\section{Hasil dan Pembahasan}

\subsection{Rantai Distribusi}

Rantai distribusi bawang merah yang dihasilkan oleh para petani di Kabupaten Rote Ndao dapat dilihat pada gambar 1, dimana stakeholders bawang merah terdiri dari para petani, pedagang pengumpul/perantara yang melakukan pengiriman antar-pulau, dan pedagang pengecer di Pasar Inpres Naikoten. Hasil identifikasi ini lebih sederhana dibandingkan dengan hasil penelitian Nurasa dan Darwis (2007) bahwa aliran rantai pasok pemasaran bawang merah di Kabupaten Brebes yang terdiri terdiri dari para petani, pedagang pengumpul, pedagang pengirim dalam pulau, pedagang pengirim luar pulau hingga pedagang pengecer di pasar induk.

Berdasarkan hasil pengamatan, terdapat 2 jenis bawang merah yang memiliki rantai distribusi masing-masing yaitu bawang merah lepasan dan askip. Jenis bawang merah tersebut memiliki tingkatan pascapanen berbeda pada saat pengirimannya.

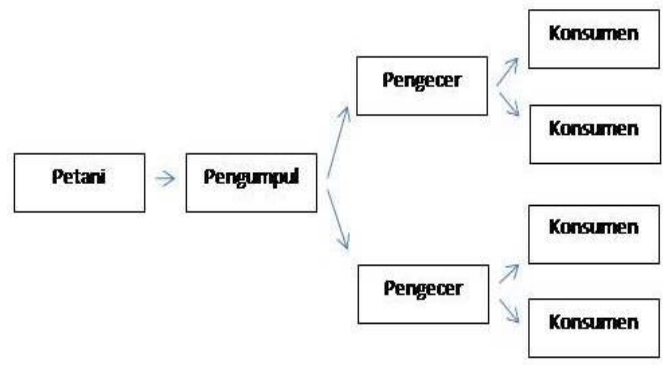

Gambar 1. Rantai Distribusi Bawang Merah

Bawang merah lepasan melalui curing dan pemotongan daun sedangkan bawang merah askip tidak dilakukan pemotongan daun namun dilakukan penjemuran lanjutan hingga mencapai askip. Gambar 2 berikut ini menampilkan kedua jenis bawang yang ada dalam rantai distribusi.
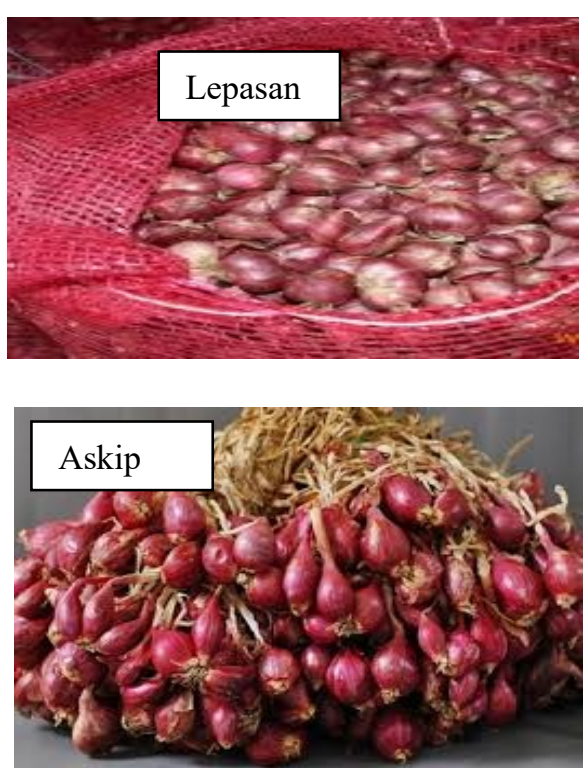

Gambar 2. Jenis Bawang Merah Yang Didistribusikan

\subsection{Rantai Nilai}

Kajian rantai nilai pascapanen telah dilakukan dengan menggunakan metode Hayami yang menunjukkan marjin, nilai tambah dan keuntungan setiap pelaku dalam rantai distribusi bawang merah dari para petani, pedagang pengumpul dan pedagang pengecer di Pasar Inpres Naikoten. Dilihat dari hasil wawancara, umumnya petani melakukan tindakan pascapanen curing dan askip, sedangkan pedagang pengumpul melakukan perdagangan dan proses distribusi ke pedagang pengecer di Pasar Inpres Naikoten dan pedagang pengecer melakukan proses jual beli langsung kepada konsumen akhir. Setiap aktivitas-aktivitas pascapanen tersebut memiliki harga, biaya dan susut yang menentukan keuntungan para pelaku dalam rantai distribusi produk. 


\subsection{Rantai Nilai Bawang Merah Lepasan}

Proses pascapanen bawang merah lepasan diawali dengan curing oleh petani, lalu pemotongan daun dan distribusi oleh pedagang pengumpul ke Pasar Inpres Naikoten, setelah itu dijual ke pedagang pengecer. Setiap aktivitas tersebut memiliki nilai tambah, keuntungan dan marjin yang berbeda-beda (tabel 3). Berdasarkan wawancara kuesioner, bawang merah lepasan melalui proses curing sehingga nilai tambah, keuntungan dan marjin diperoleh para petani. Nugraha et al (2010) pengikatan saat penjemuran curing lebih rendah kerusakaannya apabila dibandingkan dengan penjemuran tanpa pengikatan, oleh sebab itu petani dianjurkan melakukan curing terlebih dahulu.

Berdasarkan pengamatan dan wawancara dengan pedagang pengumpul, pemotongan daun dilakukan oleh pengumpul sebelum dilakukan pengiriman ke Pasar Inpres Naikoten sehingga biaya yang dikeluarkan tidak hanya transportasi namun juga biaya pemotongan daun. Biaya tersebut dalam metode Hayami merupakan sumbangan input lain sebesar $64 \%$ dari marjin. Tingginya biaya tersebut menyebabkan rendahnya keuntungan pengiriman bawang merah lepasan (Tabel 3).

Tabel 3. Analisis Rantai Nilai Bawang Merah Lepasan

\begin{tabular}{|c|c|c|c|c|}
\hline \multirow{2}{*}{\multicolumn{2}{|c|}{ Uraian }} & \multicolumn{3}{|c|}{ Bawang Merah Lepasan } \\
\hline & & $\begin{array}{c}\text { Pasca } \\
\text { panen curing } \\
\text { (Petani) }\end{array}$ & $\begin{array}{c}\text { Distribusi } \\
\text { (Pengumpul) }\end{array}$ & $\begin{array}{c}\text { Pasar } \\
\text { Inpres Naikoten } \\
\text { (Pengecer) }\end{array}$ \\
\hline \multicolumn{5}{|c|}{ A. Output, Input dan Harga } \\
\hline & Output (kg/periode) & 1040 & 6400 & 6272 \\
\hline & Bahan Baku kg/periode) & 1300 & 8000 & 6400 \\
\hline 3 & Tenaga Kerja (HOK/periode) & 12,00 & 8,00 & 5,00 \\
\hline & $\begin{array}{l}\text { Faktor Konversi (Kg output/Kg } \\
\text { bahan) }\end{array}$ & 0,80 & 0,80 & 0,98 \\
\hline 5 & $\begin{array}{l}\text { Koefisien tenaga kerja } \\
\text { (HOK/Kg Bahan) }\end{array}$ & 0,009 & 0,001 & 0,001 \\
\hline & Harga Output $(\mathrm{Rp} / \mathrm{Kg})$ & 12500 & $\frac{16000}{1600}$ & 20000 \\
\hline & $\begin{array}{l}\text { Upah rata-rata tenaga kerja } \\
(\mathrm{Rp} / \mathrm{HOK})\end{array}$ & 30000 & 30000 & 30000 \\
\hline \multicolumn{5}{|c|}{ B. Pendapatan dan Keuntungan } \\
\hline & Harga bahan $(\mathrm{Rp} / \mathrm{Kg})$ & 9500 & 12500 & 16000 \\
\hline & Sumbangan input lain $(\mathrm{Rp} / \mathrm{Kg})$ & 38 & 98 & 84 \\
\hline 10 & Nilai output $(\mathrm{Rp} / \mathrm{Kg})$ & 10000 & 12800 & 19600 \\
\hline & Nilai tambah $(\mathrm{Rp} / \mathrm{Kg})$ & 462 & 202 & 3516 \\
\hline & Rasio Nilai tambah (\%) & 4,62 & 1,58 & 17,94 \\
\hline $12 \mathrm{a}$ & Imbalan tenaga kerja $(\mathrm{Rp} / \mathrm{Kg})$ & 270 & 30 & 30 \\
\hline & Bagian tenaga kerja (\%) & 58,44 & 14,85 & 0,85 \\
\hline $13 \mathrm{a}$ & Keuntungan $(\mathrm{Rp} / \mathrm{Kg})$ & 192 & 172 & 3486 \\
\hline $\mathrm{b}$ & Tingkat keuntungan (\%) & 1,92 & 1,34 & 17,79 \\
\hline \multicolumn{5}{|c|}{ C. Balas Jasa dari Masing-masing faktor Produksi } \\
\hline & Marjin $(\mathrm{Rp} / \mathrm{Kg})$ & 400 & 1400 & 1110 \\
\hline $\mathrm{a}$ & Imbalan tenaga kerja $(\%)$ & 69,23 & 2,14 & 4,93 \\
\hline & Sumbangan lain $(\%)$ & 9,50 & 64,84 & 7,60 \\
\hline & Keuntungan (\%) & 21,27 & 33,02 & 87,47 \\
\hline D. Ra & atio RC & 1,0196 & 1,0093 & 1,2163 \\
\hline
\end{tabular}

Sumber: Data Diolah

Pada saat mendistribusikan bawang merah ke pedagang pengecer, pedagang pengumpul juga mengeluarkan biaya sewa lapak dan biaya tenaga kerja untuk proses jual beli ke pedagang pengecer. Khunt et al (2006) menyatakan bahwa terdapat variasi dalam sharing berdasarkan perbedaan saluran distribusinya. Keseluruhan hasil perhitungan Hayami sepanjang rantai distribusi bawang merah lepasan dapat dilihat pada tabel 3. Perhitungan nilai tambah Hayami (tabel 3) menunjukkan bahwa para petani yang melakukan proses curing hanya mendapatkan keuntungan sebesar Rp. 192 per $\mathrm{kg}$ atau prosentase keuntungannya hanya sebesar $1,92 \%$, dan RC Ratio yang dicapai hanya sebesar 1,0196. Pedagang pengumpul memperoleh keuntungan sebesar Rp. 172 per $\mathrm{kg}$ atau prosentase keuntungan hanya sebesar $1,34 \%$, dan RC Ratio yang dicapai hanya sebesar 1,0093. Sedangkan untuk pedagang pengecer di Pasar Inpres Naikoten dapat memperoleh keuntungan mencapai Rp. 3.486 per $\mathrm{kg}$ atau prosentase keuntungan mencapai $17,79 \%$, dan RC Ratio yang dihasilkan mencapai 1,2163.

\subsection{Rantai Nilai Bawang Merah Askip}

Dari hasil pengamatan, saluran distribusi bawang merah askip berbeda dengan bawang merah lepasan, paling banyak ditemukan tanpa melalui pedagang pengumpul sehingga lebih pendek. Menurut Sidhu et al (2010), rantai distribusi dapat panjang atau pendek, jika pendek maka rantai distribusi tidak efisien karena harga beli di tingkat petani akan menjadi tinggi sehingga harga jual di tingkat konsumen juga menjadi tinggi.

Tingginya harga jual bawang merah askip karena memiliki keunggulan umur simpan lebih lama dibandingkan bawang merah lepasan. Komponen biaya terbesar dalam proses askip berupa tenaga kerja sebesar $84 \%$ dari marjin karena membutuhkan waktu yang cukup lama hingga 7-10 hari proses penjemurannya. Keseluruhan hasil perhitungan Hayami sepanjang rantai distribusi bawang merah askip dapat dilihat pada tabel 4 .

Tabel 4. Analisis Rantai Nilai

Bawang Merah Askip

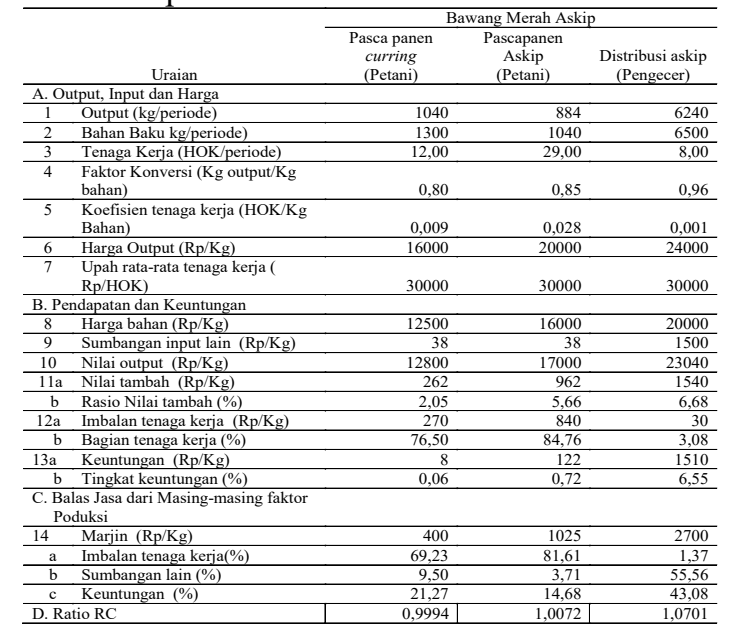

Sumber: Data Diolah

Perhitungan nilai tambah Hayami (tabel 4) menunjukkan bahwa selain melakukan curing, petani juga melakukan proses askip untuk pengiriman luar pulau agar dapat memberikan keuntungan sebesar Rp. 122 per $\mathrm{kg}$ atau sebesar $0,72 \%$ dan RC Ratio hanya sebesar 1,0072. Apabila para petani hanya melakukan proses curing tanpa askip, maka keuntungan yang diperoleh hanya sebesar Rp. 8 per $\mathrm{kg}$ atau hanya sebesar $0,06 \%$, dengan angka $\mathrm{RC}$ Ratio hanya sebesar 0,9994 . Berbeda dengan para petani, keuntungan yang diperoleh pedagang 
pengecer yang memasarkan bawang merah askip mencapai Rp. 1.510 per $\mathrm{kg}$ atau sebesar $6,55 \%$, dengan angka RC Ratio mencapai 1,0701. Proses askip membutuhkan pengeringan lebih lama dibandingkan curing sehingga susutnya lebih besar dibandingkan curing. Susut sampai askip mencapai $35 \%$. Semakin tinggi suhu dan semakin lama pengeringan kadar air bawang merah semakin rendah sehingga bobot akan menurun (Woldetsadik dan Workneh, 2010). Namun demikian, keuntungan pascapanen askip lebih tinggi dikarenakan harga jual bawang askip lebih tinggi sebesar Rp. 20.000 per kg di tingkat petani, dan Rp. 24.000 per kg di tingkat pedagang pengecer. Sedangkan harga jual bawang merah dengan proses curing tanpa askip sebesar Rp. 16.000 per $\mathrm{kg}$.

\subsection{Pemetaan Manfaat Ekonomis}

Hasil kajian rantai nilai pascapanen kedua jenis bawang merah tersebut, menunjukkan bahwa ratarata tingkat keuntungan pascapanen petani jauh lebih rendah dibandingkan dengan tingkat keuntungan yang diperoleh pedagang pengumpul dan pedagang pengecer di Pasar Inpres Naikoten. Nilai RC rasionya pun lebih rendah dibandingkan dengan pelaku lainnya, para petani memiliki RC Ratio 1,0196 untuk bawang merah lepasan, RC Ratio 0,9994 untuk proses curing tanpa askip, dan RC Ratio 1,0072 untuk bawang merah dengan proses askip. Pada pedagang pengumpul, nilai RC Ratio 1,0093 untuk jenis bawang merah lepasan. Sedangkan untuk pedagang pengecer memiliki nilai RC Ratio 1,2163 untuk jenis bawang merah lepasan, dan nilai RC Ratio 1,0701 untuk bawang merah dengan proses askip.

\section{Kesimpulan}

Petani bawang merah di Kabupaten Rote Ndao tidak memiliki alternatif rantai distribusi sehingga umumnya proses pemasaran melalui pedagang pengumpul dan pedagang pengecer untuk dapat memasarkan produknya. Kajian rantai nilai menunjukkan keuntungan pascapanen para petani lebih rendah dibandingkan dengan pedagang pengumpul maupun pedagang pengecer di Pasar Inpres Naikoten.

Para petani yang melakukan proses curing hanya mendapatkan keuntungan sebesar Rp. 192 per kg atau prosentase keuntungannya hanya sebesar 1,92\%, dengan nilai RC Ratio yang dicapai hanya sebesar 1,0196 pada produk bawang merah lepasan. Selain melakukan curing, petani juga melakukan proses askip untuk pengiriman luar pulau agar dapat memberikan keuntungan sebesar Rp. 122 per kg atau sebesar $0,72 \%$ dengan RC Ratio hanya sebesar 1,0072. Apabila para petani hanya melakukan proses curing tanpa askip, maka keuntungan yang diperoleh hanya sebesar Rp. 8 per $\mathrm{kg}$ atau hanya sebesar $0,06 \%$, dengan angka RC Ratio hanya sebesar 0,9994 .
Pada jenis bawang merah lepasan, pedagang pengumpul memperoleh keuntungan sebesar Rp. 172 per $\mathrm{kg}$ atau prosentase keuntungan hanya sebesar $1,34 \%$, dengan nilai RC Ratio yang dicapai hanya sebesar 1,0093. Sedangkan untuk pedagang pengecer di Pasar Inpres Naikoten dapat memperoleh keuntungan mencapai Rp. 3.486 per $\mathrm{kg}$ atau prosentase keuntungan mencapai $17,79 \%$, dengan nilai RC Ratio yang dihasilkan mencapai 1,2163. Pada jenis bawang merah askip, keuntungan yang diperoleh pedagang pengecer yang memasarkan bawang merah jenis ini mencapai Rp. 1.510 per $\mathrm{kg}$ atau sebesar $6,55 \%$, dengan nilai RC Ratio mencapai 1,0701 .

Nilai RC lebih dari satu menujukkan bahwa petani, pengirim dan pedagang pasar induk tidak mengalami kerugian. Namun demikian, salah satu ukuran perdagangan yang adil dapat ditunjukkan dengan RC Ratio yang hampir sama sepanjang rantai distribusi produk tersebut.

Dengan demikian, hasil identifikasi rantai distribusi dan kajian rantai nilai kedua jenis bawang merah tersebut, menunjukkan bahwa manfaat ekonomis yang diterima oleh para petani bawang merah di Kabupaten Rote Ndao jauh lebih rendah dibandingkan dengan manfaat ekonomis yang diterima oleh para pedagang pengumpul dan pedagang pengecer di Pasar Inpres Naikoten.

Berdasarkan analisis rantai nilai, perlu ada intervensi pascapanen untuk meningkatkan nilai tambah bagi petani berupa pengurangan susut dengan cara perbaikan proses curing dan penerapan teknologi penyimpanan yang lebih baik untuk antisipasi faktor musiman. Perbaikan curing yang dapat dilakukan berupa penerepan standar operasional prosedur pascapanen bawang merah lebih ketat. Kementrian Pertanian (2011), telah mengeluarkan standar operasional curing seperti pengikatan yang lebih teratur agar tidak tercecer, pembalikan ikatan lebih terjadwal agar bagian dalam ikatan daun terkena sinar matahari secara merata serta penutupan lebih rapat bila malam hari.

\section{Ucapan Terima Kasih (Acknowledgments)}

Peneliti menyampaikan terima kasih kepada Direktur dan Pusat Penelitian dan Pengabdian Masyarakat Politeknik Pertanian Negeri Kupang yang telah menyetujui dan bersedia membiayai penelitian ini. Ucapan terima kasih juga Peneliti sampaikan kepada Pemerintah Kabupaten Rote Ndao dan semua pihak yang telah membantu dengan caranya masing-masing, untuk kelancaran penyelesaian kegiatan penelitian ini.

\section{Referensi}

ACIAR. 2012. Membuat Rantai Nilai Lebih Berpihak pada Kaum Miskin.Australian Center for International Agriculture 
Research. Buku Pegangan untuk Praktisi Rantai Nilai. Tabros Indonesia

Bahtiar J, Kindangen G. 2011. Penerapan Rantai Nilai (Value Chain Analysis) dalam Rangka Akselerasi Pembangunan Sektor Pertanian di Sulawesi Utara. Balai Pengkajian Teknologi Pertanian (BPTP). Sulawesi Utara

Balk BM. 2002. The Residual: On Monitoring and Benchmarking Fims, Industries, and Economics with Respect to Productivity. Netherlands: Erasmus University Rotterdam Press

Boade VA. 2003. A Conversation About Value Adde Agriculture. Departement of Agriculture Economics, Kansas State University

Direktorat Jendral Pengolahan dan Pemasaran Hasil Pertanian. 2016. Road map Pascapanen dan Pemasaran Hasil Pertanian. Kementerian Pertanian RI

Endrasri R, Prayudi B. 2011. Teknologi Penanganan Bawang Merah dan Aspek Teknologi Produk Olahannya Untuk Peningkatan Nilai Tambah di Kabupaten Brebes. Risalah Hasil Penelitian "Inovasi Hortikultura di Jawa Tengah". Badan Penelitian dan Pengembangan Pertanian Balai Besar Pengkajian dan Pengembangan Teknologi Pertanian Balai Pengkajian Teknologi Pertanian di Jawa Tengah

FAO.2012. Study on Market Appraisal and Value Chain Development of Chili Products in West Java Food Agriculture Organization, 2012

Gittinger JP.1972. Economic Analysis of Agricultural Project. The Johns Hopkins University Press, Baltimore and London

Hayami Y, Toshihiko, Kawagoe, Yoshinori Marooka, Masdjidin Siregar. 1987. Agricultural Marketing and Processing in Upland Java. A Perspective From A Sunda Village. CGPRT Center. Bogor. $75 \mathrm{p}$

Khunt KA, Gajipara HM, Venkariya SB. 2006. Price behaviour of major vegetables in Gujarat State. Indian Journal of Agricultural Marketing, 20: 28-37

Kumar BG, Pramanik SC, Nawaz S. 2004. Economics of production and marketing of vegetables in Andaman and Nicobar Islands. Indian Journal of Agricultural Marketing, 18: $16-22$

Mayrowani H, Agustin NK, Swastika DK, Aziz M. 2013. Analisis Struktur Perilaku Kinerja Pemasaran Sayuran Bernilai Ekonomi Tinggi. Laporan Akhir. Pusat Penelitain dan Pengembangan Sosial Ekonomi Pertanian

Navadkar DS, Sale DL, Patil UD. 2005. Marketing of vegetables grown around Pune city. Agricultural Situation in India, 63: 259-65
Nurasa T, Darwis V. 2007. Analisis Usahatani dan Keragaman Marjin Pemasaran Bawang Merah di Kabupaten Brebes. Jurnal Akta Agrosia Vol. 10 No 1 hlm 40-48

Prihatiningsih N. 2007. Analisis Efisiensi pasokan Bawang Merah. Skripsi. Fakultas Teknologi Pertanian. IPB

Sidhu RS., Sanjay K, Kamal V, dan Parminder S. 2010. Supply Chain Analysis of Onion and Cauliflower in Punjab. Agricultural Economics Research Review. Vol. 23 (Conference Number) 2010 pp 445-453

Stephen P. D'Alessandro of The Sahel Group. 2008. Malian Shallot Value Chain Study. Initiatives Intégrées pour la Croissance Economique au Mali (IICEM)

Triyono, Rosyadi I, Ahyani F. 2010. Efisiensi Pengelolaan Pasar Bawang Merah Kabupaten Cirebon. Dinamika Sosial Ekonomi Vol. 6 No. 1

Woldetsadik SK, Workneh TS. 2010. Effect of Nitrogen level, Harvesting time and Curing on Quality of Shallot Bulb. African Journal of Agricultural Research Vol. 5(24), pp. 3342-3353 